\section{Visiting Outdoor Green Environments Positively Impacts Self-rated Health among Older People in Long-term Care}

\author{
Erja Rappe ${ }^{1}$, Sirkka-Liisa Kivelä² , and Hannu Rita ${ }^{3}$
}

\begin{abstract}
ADDITIONAL INDEX WORDS. quality of life, human well-being, outdoor visit, park, accessibility, nursing home

SumMARY. The restorative effects of nature in enhancing human well-being are well documented. However, the effects of exposure to a green environment on health in institutional settings have not been adequately studied. Our study describes the relationship between the reported frequency of visits to an outdoor green environment and self-rated health, including hindrances experienced during outdoor visits among older people living in a nursing home. Forty-five women assessed their health and answered a questionnaire containing the Nottingham Health Profile (NHP) during an interview. A strong positive association was established between the reported frequency of visiting outdoors and selfrated health even when taking into account health-related distresses measured using the NHP $(\mathrm{B}=\mathbf{0 . 2 3 5}, P<0.01)$. The main hindrances related to outdoor visits were lack of assistance and uncomfortable weather conditions. The results suggest that it might be possible to promote the well-being of older individuals living in nursing homes by providing them with opportunities to visit outdoor green environments. By increasing the accessibility and attractiveness of the outdoor environment, the frequency of outdoor visits could increase, resulting in better perceived health. Implementation of environmental interventions that facilitate year-round outdoor visits are recommended.
\end{abstract}

S elf-rated health is a widely used measure of health in which various health-related issues are taken into account. Disabilities, chronic diseases, and symptoms such as lack of energy and pain are determinants of self-rated health (Manderbacka et al., 1999; Molarius and Janson, 2002; Noro and Aro, 1996; Shadbolt, 1997). Self-rated health predicts the use of health care services, morbidity, and even mortality, indicating its validity as a measure of overall health (Miilunpalo et al., 1997; Shadbolt, 1997).

There is no unanimity among researchers as to whether quality of life and health are distinct constructions (Lercher, 2003; Smith et al., 1999). Considerable agreement exists, however, on the subjective and multidimensional nature of the quality of life,

${ }^{1}$ Corresponding author; Department of Applied Biology, PO Box 27, C-House, 00014 University of Helsinki Finland; e-mail address: erja.rappe@helsinki.fi

${ }^{2}$ Professor, Unit of Family Medicine, Turku University Hospital and Satakunta Central Hospital, Lemminkäisenkatu 1, 20014 University of Turku, Finland.

${ }^{3}$ Docent, Department of Forest Resource Management, Statistics and Methodology, PO Box 27, 00014 University of Helsinki, Finland.

This research was supported by the Emil Aaltonen Foundation, the Kemira Foundation, and The Finnish Cultural Foundation. including both positive and negative dimensions of physical, psychologi$\mathrm{cal}$, and social domains (WHOQOL Group, 1995).

Research on the structure of selfrated health has usually focused on the effects of various impairments and diseases that have a negative impact on self-rated health (Manderbacka et al., 1999; Miilunpalo et al., 1997; Shadbolt, 1997). According to Downie et al. (2000), the concept of health captures not only negative features such as diseases and disabilities, but also positive aspects such as well-being and fitness. In their model, health can be promoted by increasing positive health, reducing negative health, or both.

There are reasons to suppose that exposure to nature can improve self-rated health since it is associated with positive health outcomes. The restorative effects of nature in enhancing well-being are well documented. Seeing greenery or being in nature reduces stress, promotes attention capacity, and improves mood (Grahn and Stigsdotter, 2003; Hartig et al., 2003; Kaplan and Kaplan, 1989; Laumann et al., 2003; Tennessen and Cimprih, 1995; Ulrich et al., 1991). Plants and nature are also associated with better pain control. In laboratory studies, the presence of ornamental plants improved pain tolerance (Lohr and Pearson-Mims, 2000; Park et al., 2004). Flowering plants had marked positive effects on pain tolerance time, pain intensity, and pain distress among female university students (Park et al., 2004). For patients undergoing bronchoscopy, views and sounds of nature significantly reduced pain (Diette et al., 2003). In addition, green environments may indirectly enhance well-being by promoting physical exercise. In a cohort study, walkable green spaces near residential environments increased the probability of 5-year survival of senior citizens in Tokyo (Takano et al., 2002).

Studies of older people living in institutions indicate positive associations between well-being of the residents and closeness of a green environment. Visiting an outdoor green environment is associated with better ability to concentrate and improved mood among the older people living in nursing homes (Ottosson and Grahn, 1998; Rappe and Kivelä, 2005). Retirement home residents benefited in terms of improved well-being and satisfaction with life by looking from windows at green environments and visiting recreational areas (Brascamp and Kidd, 2004). Plants and garden environments may contribute to psychological and social well-being of older people with dementia, according to nursing staff (Rappe and Lindén, 2004). Some studies also established that visits to gardens decreased agitation and aggression in demented persons (Cohen-Mansfield, 2001; Day et al., 2000).

The health-related quality of life of older Finns in residential care is significantly poorer than among non-institutionalized older people. Difficulties in functional abilities are particularly common among institutionalized older people. For example, the proportion of institutionalized older men and women with no difficulty in moving outdoors is much lower than that for non-institutionalized older people (Noro and Aro, 1996).

Although health-related factors can impact on self-rated health among the older people living in nursing care, the results from previous studies indicate that outdoor visits may also affect it. It is suggested that the more often older people visit outdoors, the better their self-rated health is. As 
poor health may have a confounding impact on the effects of outdoor visits, it is important to analyze how healthrelated factors, such as physical mobility and social isolation, are associated with the frequency of outdoor visits and whether they have an impact on the effect of outdoor visits on self-rated health. The poor functional abilities of institutionalized older people may limit their possibilities to visit outdoors. It is important to document the factors that older people feel restrict their visits outdoors.

The purpose of this study was to describe the relationship between the reported frequency of outdoor visits to a green environment and self-rated health among older people living in a nursing home. It was hypothesized that with increasing frequency of outdoor visits, self-rated health improves. In addition, factors having an impact on the accessibility of an outdoor environment in a long-term care institution were analyzed.

\section{Subjects}

The participants for the study ( 45 women) were chosen from among the residents of Kustaankartano nursing home and service center in Helsinki, Finland. Initially the data included 10 men, but they were dropped because it was not reasonable to perform statistical analysis within so small a group. The participants were separated by gender since it seemed possible that there might be gender differences. For example, men visited the outdoors more frequently, year-round, than women. Kustaankartano comprises nine residential blocks for older people, who live mainly in single rooms. The residential blocks are randomly arranged in a circular landscaped area of 8 ha (19.8 acres). In the center is a wide park with walking paths and a pond. The walking paths are mainly wheelchair accessible. All persons were in long-term care and lived in three of the residential blocks. Their mean age was 85 years (range $=64-98$ years) .

The data were gathered in July and Aug. 2001 by the first author, E. Rappe. Selection of the participants was based on the recommendations of charge nurses. The ability to answer questions independently in the interview was a requirement for participation. The participants had no major cognitive, hearing, or speech impairments. One of them had a visual impairment limiting her ability to see bluish colors. Three of the recommended residents refused. Interviews were mainly conducted in the rooms of the participants.

\section{Measurements}

Self-rated health was assessed using the question: "At the present time, would you say that your health is excellent, very good, good, fair, or poor?" Health-related quality of life was measured using the Nottingham Health Profile, which consists of 38 binary "yes" or "no" items addressing distresses in physical, medical, and social health. NHP is a profile measure consisting of six dimensions related to health: energy level, sleep, pain, physical mobility, emotional reactions, and social isolation. For example, the items for the energy level (translated from the Finnish version) were as follows: 1) I am tired all the time; 2) all activities need hard work to try; 3 ) I become exhausted quickly. A summed score was calculated for each dimension of every participant by weighting "yes" answers for every item. The weights were derived from a representative Finnish population sample. The Cronbach's alpha coefficients for various dimensions of the scale in the population sample were as follows: energy level 0.70 , sleep 0.76 , pain 0.88 , emotional reactions 0.85 , social isolation 0.73 , and physical mobility 0.82 . The range of the scale is 0 to 100 , with higher values indicating poor health-related quality of life (Koivukangas et al., 1995).

Visiting outdoors was defined as either entering the courtyard or being on the balcony. Visits to the balcony were included since they enabled passive nature experiences. The decision as to whether to go out or not was the responsibility of the residents. The frequency of visiting outdoors was addressed by the question: "How often do you visit outdoors?" Answers were divided into five groups: never, sometimes yearly, sometimes monthly, sometimes weekly, and daily. A questionnaire including items related to visiting outdoors (season of visiting, accompanying person, where to go and what to do there, experienced hindrances) was completed during the interview.

In addition, demographic variables (age, length of stay in institutions) were recorded. The staff assessed physical functional abilities on a scale from $\mathrm{l}=$ independent to $5=$ bedridden and requiring help in all activities. None of the participants were bedridden. Forty-nine percent of the participants needed assistive devices and constant help in moving, according to staff assessments. The age of the participants was not associated with the use of the assistive devices $(\mathrm{t}=-0.583, \mathrm{df}=43$, $P=0.563$ ).

\section{Analyses}

The demographic data were analyzed using descriptive statistics. The $t$ test was used to analyze differences in self-rated health between those visiting outdoors year round and only in summer and to analyze if the mean age among those using assistive devices was different from those not using assistive devices. Equality of variances was tested with Levene's test. Associations between the reported frequency of visiting outdoors and separate NHP dimensions were determined using Spearman correlation coefficient. Associations between the reported frequency of visiting outdoors, NHP dimensions, and self-rated health were analyzed using linear regression analysis. Cronbach's alpha coefficients were computed for the sumscores of the NHP dimensions to judge the reliability of the scale. The reliability coefficients of the NHP dimensions ranged from 0.58 to 0.78 . All statistical analyses were conducted using SPSS (version 10; SPSS Inc., Chicago).

\section{Results}

Self-RATED HeAlth AND ITS ASSOCIATIONS WITH HEALTH-RELATED QUALITY OF LIFE MEASURED BY NHP. In total, $33 \%$ of the participants reported their health to be poor or very poor and $67 \%$ reported their health to be good or very good. None of them reported their health to be excellent. On average, the study population had a lower quality of life in all dimensions compared with the general Finnish older population (Table 1). In the study population, mobility and energy level were the poorest quality of life dimensions and social isolation the highest.

In linear regression models adjusted for age, the factors for self-rated health in this data were energy level, pain, and physical mobility (Table 2).

Visiting OUTDOORS: FREQUENCY, PERCEIVED HINDRANCES, AND OBJECTS OF INTEREST. Reported outdoor visits 
were more frequent in summer than in winter. Two out of three participants reported visits outdoors in summer and only one out of five reported visits outdoors year round. In total, $67 \%$ of them reported visits outdoors daily or weekly at least during summer. One participant reported no outdoor visits at all. Of the participants, $49 \%$ said they visited outdoors only with staff, $20 \%$ with relatives, $13 \%$ with both staff and relatives, and $11 \%$ alone. Use of walking aids and wheelchairs did not seem to be associated with the frequency of visiting outdoors.

The main reasons restricting outdoor visits were the lack of assistance (mentioned by $38 \%$ of the participants) and uncomfortable weather conditions $(29 \%)$. Steep or uneven paths were mentioned by $11 \%$ of the participants as restricting factors, and heavy and locked doors and doorsteps by $9 \%$ of the participants. Only $11 \%$ of the participants out of 45 indicated that their poor health restricted outdoor visits.

All participants except four wanted to visit outdoors. Two of the latter persons considered their health so poor that they felt visiting outdoors too burdensome. One told of environmental restrictions and one felt a desire for privacy to be the reasons for not visiting outdoors.

In total, $78 \%$ of the participants mentioned nature-related aspects, including observing nature or walking in the park, when they were asked what they do outdoors. The park-like area and the pond in the center of the courtyard were highly appreciated by those older people. When they were engaged in the observation of nature, pains and other distresses were not evident. They considered large trees important: looking at trees imparted a feeling of tranquillity. Flowering and fragrant plants and singing birds were frequently mentioned as objects of observation.

VISITING OUTDOORS AND SELFRATED HEALTH. In the linear regression model, the reported frequency of visiting outdoors had a strong positive effect on self-rated health (Table 3 ). The season for outdoor visits was not associated with self-rated health. Those who reported to visit outdoors year round did not have better self-rated health than those visiting outdoors only in summer $(\mathrm{t}=-0.811, \mathrm{df}=41, P=$ $0.422)$. No statistically significant correlations were established between the

Table 1. The sumscores of Nottingham Health Profile (NHP) dimensions measuring health-related quality of life in a general elderly (75-80 years) Finnish population $^{\mathrm{z}}$ and in the study population of older Finnish women living in nursing care. The range of the scale is $0-100$, higher values indicating poor healthrelated quality of life.

\begin{tabular}{lcc}
\hline & \multicolumn{2}{c}{ Sumscores } \\
\cline { 2 - 3 } NHP dimension & $\begin{array}{c}\text { General population, } \\
\text { both genders, } \mathbf{n}=\mathbf{1 7 6} \\
(\text { mean } \pm \text { SD })\end{array}$ & $\begin{array}{c}\text { Study population, } \\
\text { women, } \mathbf{n}=\mathbf{4 4}-\mathbf{4 5} \\
(\mathbf{m e a n} \pm \mathbf{S D})\end{array}$ \\
\hline Energy level & $32.6 \pm 38.0$ & $50.03 \pm 38.39$ \\
Sleep & $30.2 \pm 35.6$ & $38.12 \pm 31.53$ \\
Pain & $27.9 \pm 32.1$ & $35.79 \pm 27.69$ \\
Emotional reactions & $16.5 \pm 24.4$ & $25.47 \pm 25.93$ \\
Social isolation & $10.7 \pm 19.1$ & $20.78 \pm 24.25$ \\
Physical mobility & $28.9 \pm 28.3$ & $60.58 \pm 24.37$ \\
\hline
\end{tabular}

${ }^{2}$ Koivukangas et al., 1995.

Table 2. Age-adjusted coefficients (B) for dimensions of health-related quality of life measured by Nottingham Health Profile (NHP) in univariate linear regression models predicting self-rated health among older Finnish women living in nursing care.

\begin{tabular}{lcccc}
\hline NHP dimension & B & SE & $P$ & $\mathbf{n}$ \\
\hline Energy level & -0.013 & 0.002 & 0.000 & 45 \\
Sleep & -0.001 & 0.004 & 0.870 & 45 \\
Pain & -0.014 & 0.004 & 0.000 & 45 \\
Emotional reactions & -0.007 & 0.005 & 0.154 & 44 \\
Social isolation & -0.008 & 0.005 & 0.113 & 45 \\
Physical mobility & -0.010 & 0.005 & 0.045 & 45 \\
\hline
\end{tabular}

Table 3. Coefficient (B) for the reported frequency of visiting outdoors in linear regression models predicting self-rated health alone and adjusted for age and dimensions of health-related quality of life measured by Nottingham Health Profile.

\begin{tabular}{lccccc}
\hline & B & Adjusted & & & \\
& $\mathbf{R}^{2}$ & SE & $P$ & $\mathbf{n}$ \\
\hline $\begin{array}{l}\text { Frequency of outdoor visits } \\
\text { Adjusted for }\end{array}$ & 0.322 & 0.220 & 0.088 & 0.001 & 45 \\
$\quad$ Age & & & & & \\
$\quad$ + separately for & 0.322 & 0.202 & 0.089 & 0.001 & 45 \\
$\quad$ Energy level & & & & & \\
$\quad$ Sleep & 0.255 & 0.375 & 0.070 & 0.001 & 45 \\
$\quad \begin{array}{l}\text { Pain } \\
\quad \text { Emotional reactions }\end{array}$ & 0.322 & -0.047 & 0.090 & 0.001 & 45 \\
$\quad$ Social isolation & 0.255 & 0.237 & 0.081 & 0.003 & 45 \\
$\quad \begin{array}{l}\text { Physical mobility } \\
\text { Adjusted for all variables }\end{array}$ & 0.332 & 0.003 & 0.087 & 0.000 & 44 \\
$\quad$ & 0.292 & 0.014 & 0.087 & 0.001 & 45 \\
$\quad$ & 0.235 & 0.466 & 0.077 & 0.004 & 44 \\
\hline
\end{tabular}

reported frequency of visiting outdoors and separate NHP dimensions.

Linear regression analysis adjusted for age was used to examine the role of mobility as related to the effects of the reported frequency of outdoor visits on self-rated health. The participants were grouped according to staff assessments to independently mobile (i.e., not using assistive devices) and to dependently mobile (i.e., using assistive devices). The regression coefficient for the reported frequency of visiting outdoors was highly significant in a one-sided test $(\mathrm{B}=0.446, \mathrm{n}=23, P=0.0015)$ among independently mobile women, indicating better self-rated health with increasing frequency of outdoor visits. Among dependently mobile women the regression coefficient remained positive $(\mathrm{B}=0.177, \mathrm{n}=22, P=0.079)$ in a one-sided test. The difference between regression coefficients among independently mobile and dependently mobile women was tested in a onesided interaction test, indicating pos- 
sible differences. The difference of the regression coefficient (independently mobile - dependently mobile) was $0.265(\mathrm{n}=45, P=0.072)$.

To examine whether the relationship between the reported frequency of outdoor visits and self-rated health still existed when the health-related quality of life was controlled, a series of linear regression analyses were conducted. This was made to assess whether the observed association between self-rated health and visiting outdoors was independent or whether the dimensions of health-related quality of life influenced the association. In these analyses both the reported frequency of visiting outdoors and NHP dimensions adjusted for age were used separately as predictors for self-rated health. Lastly, all independent variables studied were entered into the analysis simultaneously.

The effect of the frequency of visiting outdoors on self-rated health decreased, but not to zero, when controlling for energy level and pain. It remained similar when distresses in sleep, physical mobility, social isolation, and emotional reactions were held constant (Table 3 ).

In the linear regression model when all NPH dimensions (energy level, sleep, pain, physical mobility, emotional reactions, and social isolation), age, and the reported frequency of visiting outdoors were included, the positive association between the frequency of visiting outdoors and selfrated health remained (Table 3 ).

\section{Discussion}

A strong positive association emerged between the reported frequency of visiting outdoors and selfrated health among the older women living in long-term nursing care. The regression coefficient for the reported frequency of visiting outdoors remained stable when adjusting for the six health-related distresses measured using the NHP and it was positive even among the participants using wheelchairs and walking aids when visiting outdoors. The result suggests that visiting outdoors may enhance self-rated health independently among older women living in long-term institutional care despite their many health problems.

No statistically significant correlations were established between the reported frequency of outdoor visits and separate NHP dimensions. One reason for that may be the binary NHP not being sensitive enough to detect the health-promoting aspects of visiting outdoors.

Most of the participants in the study wanted to visit outdoors. It is noteworthy that only $11 \%$ suggested that health-related problems restricted visiting outdoors. The most frequently mentioned hindrance related to outdoor visits was lack of assistance. To increase staff resources for outdoor visits may be a problem. Considering outdoor visits as an important part of nursing care, having positive health effects on residents may motivate the staff to provide more assistance to the older people.

Weather conditions were the second most often cited restriction to visiting outdoors. Cold and windy weather and slippery walks were considered to be particular hindrances. Weather conditions as restricting factors are probable since during the winter months (December-February) the mean temperature is $-3.8^{\circ} \mathrm{C}(25.16$ ${ }^{\circ} \mathrm{F}$ ) in southern Finland (Drebs et al., 2002). The only way to obviate the effects of adverse weather is to provide sheltered outdoor environments and maintain walking paths in good condition.

Mobility was associated with self-rated health in this and previous studies (Jylhä et al., 2001; Noro and Aro, 1996). Mobility is influenced by environmental factors, as walking difficulties are partly dependent on the accessibility of the environment. According to behavioral choice theory, changes in environment that increase the proximity and convenience of physical activity can increase the frequency of physical activity (Epstein, 1998). It is important to remove hindrances such as heavy doors and thresholds that prevent outdoor visits of people who are not independently mobile. For those without mobility limitations, increasing the attractiveness and convenience of the outdoor environment may increase the frequency of outdoor visits and result in better perceived health. Environmental interventions facilitating year-round outdoor visits should be implemented.

Participants who visited outdoors during all seasons did not have better self-rated health than those who visited outdoors only in summer. One explanation for this result may be that this study was undertaken in summer, when the majority of the participants were frequently outside and their ratings of self-rated health were made when they felt themselves to be healthy. In addition, in Finland it is normal to restrict outdoor visits among old people during winter because of the danger of falling on slippery walks. This practice may be reflected in the estimates of self-rated health.

The results of this study indicate that there may be additional aspects of health-promoting effects related to visiting outdoors other than an increased amount of physical activity. First, although the reported frequency of visiting outdoors was not so strongly associated with self-rated health among the women with mobility limitations than among independently mobile women, the effect of high frequency of outdoor visits on self-rated health was positive even among them. Second, none of the health distresses measured by NHP was significantly correlated with the frequency of visiting outdoors. Third, because the effect of the frequency of visiting outdoors on self-rated health remained relatively unchanged when NHP dimensions were held constant, it can be assumed that the effect of visiting outdoors was not confounded by these dimensions.

Nature has a strong attentionholding capacity (Kaplan and Kaplan, 1989) that may be associated with better pain tolerance when looking at plants (Lohr and Perason-Mims, 2000; Park et al., 2004) and natural landscapes (Diette et al., 2003). Better coping with pain and other troubles when visiting outdoors may decrease stress and result in improved self-rated health. In previous studies, a positive mood shift and better ability to concentrate were associated with visiting an outdoor green environment among the older people living in nursing homes (Ottosson and Grahn, 1998; Rappe and Kivelä, 2005). The improved self-rated health associated with outdoor visits might reflect an enhanced emotional and cognitive well-being resulting from exposure to nature, especially among the most dependent participants. Those who are independently mobile obviously will get more physical exercise outdoors and that in turn may lead to better perceived health.

The effects of the physical environment on health among the older 
people living in long-term care have not been adequately examined. Despite these findings, based on a cross-sectional study with a small number of participants, conclusions concerning causality remain unclear. Further research is needed to establish possible causal relationships and to define the factors of physical environment that affect health, particularly the factors enhancing psychological well-being.

In conclusion, the results of this study suggest that outdoor visits may have a positive effect on the self-rated health of the older people in longterm institutional care. Not all chronic diseases and impairments of the older people can be cured. However, it may be possible to promote their well-being in spite of these impediments by providing opportunities for outdoor visits.

\section{Literature cited}

Brascamp, W. and J.L. Kidd. 2004. Contribution of plants to the well-being of retirement home residents. Acta Hort. 639:145-150

Cohen-Mansfield, J. 2001. Nonpharmacologic interventions for inappropriate behaviours in dementia. Amer. J. Geriatric Psychiatry 9:361-381.

Day, K., D. Carreon, and C. Stump. 2000. The therapeutic design of environments for people with dementia. Gerontologist 40:397-416.

Diette, G., N. Lechtzin, E. Haponik, A. Devrotes, and H. Rubin. 2003. Distraction therapy with nature sights and sounds reduces pain during flexible bronchoscopy. Chest 123:941-948.

Downie, R.S., C. Tannahill, and A. Tannahill. 2000. Health promotion models and values. 2nd ed. Oxford Univ. Press, Oxford, U.K.

Drebs, A., A. Norlund, P. Karlsson, J. Helminen, and P. Rissanen. 2002. Tilastoja Suomen ilmastosta 1971-2000-Climatological statistics of Finland 1971-2000. Ilmatieteen laitos, Helsinki, Finland.

Epstein, L.E. 1998. Integrating theoretical approaches to promote physical activity. Amer. J. Preventive Medicine $15: 257-265$
Grahn, P. and U.A. Stigsdotter. 2003. Landscape planning and stress. Urban For. Urban Greening 2:001-018.

Hartig, T., G.W. Evans, L.D. Jamner, D.S. Davis, and T. Gärling. 2003. Tracking restoration in natural and urban field settings. J. Environ. Psychology 23:109-123.

Jylhä, M., J. Guralnik, J. Balfour, and L. Fried. 2001. Walking difficulty, walking speed, and age as predictors of self-rated health: The women's health and aging study. J. Gerontology 56A:M609-M617.

Kaplan, R. and S. Kaplan. 1989. The experience of nature. A psychological perspective. Cambridge Univ. Press, Cambridge, U.K.

Koivukangas, P., A. Ohinmaa, and J. Koivukangas. 1995. Nottingham health profilen (NHP) suomalainen versio. Raportteja 187. Stakes, Helsinki, Finland.

Laumann, K., T. Gärling, and K.M. Stormark. 2003. Selective attention and heart rate responses to natural and urban environments. J. Environ. Psychology 23:125-134.

Lercher, P. 2003. Which health outcomes should be measured in health related environmental quality of life studies? Landscape Urban Planning 65:63-72.

Lohr, V. and C. Pearson-Mims. 2000. Physical discomfort may be reduced in the presence of interior plants. HortTechnology $10: 53-58$.

Manderbacka, K., O. Lundberg, and P. Martikainen. 1999. Do risk factors and health behaviours contribute to selfratings of health? Social Sci. Medicine 48:1713-1720.

Miilunpalo, S., I. Vuori, P. Oja, M. Pasanen, and H. Urponen. 1997. Self-rated health status as a health measure: The predictive value of self-reported health status on the use of physician services and on mortality in the working-age population. J. Clinical Epidemiology 50:517-528.

Molarius, A. and S. Janson. 2002. Self-rated health, chronic diseases, and symptoms among middle-aged and elderly men and women. J. Clinical Epidemiology 55:364-370.
Noro, A. and S. Aro. 1996. Health-related quality of life among the least dependent institutional elderly compared with the non-institutional elderly population. Quality Life Res. 5:355-366.

Ottosson, J. and P. Grahn. 1998. Utemiljöns betydelse för äldre med stort vårdbehov. Stad and Land nr 155. Förvaltningsavdelningens repro vid SLU, Alnarp, Sweden.

Park, S.-H., R.H. Mattson, and E. Kim. 2004. Pain tolerance effects of ornamental plants in a simulated hospital patient room. Acta Hort. 639:241-247.

Rappe, E. and S.-L. Kivelä. 2005. Visiting a garden in long-term care: Experiences of the aged in relation to depression. HortTechnology 15:298-303.

Rappe, E. and L. Lindén. 2004. Plants in health care environments: Experiences of the nursing personnel in homes for people with dementia. Acta Hort. 639:75-81.

Shadbolt, B. 1997. Some correlates of selfrated health for Australian women. Amer. J. Public Health 87:951-956.

Smith, K., N. Avis, and S. Assmann. 1999. Distinguishing between quality of life and health status in quality of life research: A meta-analysis. Quality Life Res. 8:447-459.

Takano, T., K. Nakamura, and M. Watanabe. 2002. Urban residential environments and senior citizens' longevity in megacity areas: The importance of walkable green spaces. J. Epidemiological Community Health 56:913-918.

Tennessen, C. and B. Cimprich. 1995. Views to nature: Effects on attention. J. Environ. Psychology 15:77-85.

Ulrich, R.S., R.F. Simons, B.D. Losito, E, Fiorito, M.A. Miles, and M. Zelson. 1991. Stress recovery during exposure to natural and urban environments. J. Environ. Psychology 11:201-230.

WHOQOL Group. 1995. The World Health Organization quality of life assessment (WHOQOL): Position paper from the World Health Organization. Social Sci. Medicine 41:1403-1409. 